\title{
PARA UNA SOCIOLOGIA DE LA PRENSA. INTRODUCCION A UN TEXTO DE MAX WEBER
}

El texto de Max Weber que, por vez primera, se publica ahora en español, sugiere dos reflexiones de muy diversa índole. La primera, general por su naturaleza, se refiere a una dimensión de la obra de Max Weber menos conocida que sus grandes aportaciones teóricas y metodológicas. Aparece aquí el Weber impulsor de la investigación empírica, preocupado por el descubrimiento de nuevos temas para el estudio científico, de entre los que componen el entramado de la sociedad alemana y occidental de su tiempo. Se trata, además, de una faceta de la obra maxweberiana que se proyecta a través de asociaciones profesionales. Así, a través de la Asociación Alemana de Política Social, los hermanos Max y Alfred Weber propondrán en 1907 la realización de una encuesta sobre selección y adaptación (elección de profesión y destino profesional) de los trabajadores de la gran industria. Max Weber insistirá, un año más tarde, al llevar a cabo la introducción metodológica a dicha encuesta, sobre el carácter científico social y no político social de la misma ${ }^{1}$. Tal encuesta marcará el comienzo de la sociología industrial, en un momento en que la atención científica sobre el trabajo se centraba, tanto en Inglaterra como en Estados Unidos, sobre sus aspectos médicos y psicológicos. Del mismo modo, pero esta vez en el marco de la Asociación Alemana de Sociología, Weber propondrá como

1 Max Weber, «Das Berufsschicksal des Industriearbeiters», en Arcbiv für Socialwissenschaften und Sozialpolitik, tomo 34, 1912. 
objetos de estudio la prensa y las organizaciones formales alemanas. Será, precisamente, el contenido de su alocución en el Primer Congreso de la Asociación Alemana de Sociología, celebrado en Frankfurt, en 1910.

Lo que llama poderosamente la atención aquí, es la profunda y certera visión sociológica de Max Weber, dicho sea con expresión de Hans Freyer ${ }^{2}$. Su capacidad para ver la sociedad en la cual se desenvuelve, con mentalidad de sociólogo y, en consecuencia, su capacidad para descubrir nuevos objetos susceptibles de consideración científico-social, sobre los cuales nunca otro antes hubiera reparado. Pero, por la misma razón que reflexiona sobre contenidos de experiencia que son comunes a todos los hombres de su tiempo y sobre los cuales comparte con los demás -incluido el hombre de la calle-, tanto el saber como la ignorancia, lo que Weber aconseja y pone en práctica es el sencillo tránsito - sencillo, al menos en apariencia-, desde la experiencia cotidiana a la formulación de preguntas científicas. Y esto, en lenguaje preciso y riguroso, con escasa formalización conceptual, asequible a todos los entendimientos. En ninguno de sus escritos metodológicos alcanzará Weber a explicar mejor cómo bay que proceder para ponerse en el camino de la ciencia sociológica, a partir de la experiencia común.

Si bien es cierto que durante muchos años ha estado desatendida - al menos, entre nosotros- la consideración de este aspecto tan sugestivo del quehacer científico de Max Weber, no es mi intención, aquí y ahora, dedicar más espacio a tal tema. De las dos reflexiones a las que he aludido al comienzo de estas líneas, será más relevante, por específica, la que se refiere al contenido concreto del texto que presentamos.

La alocución de Max Weber a sus colegas de la Asociación Alemana de Sociología, con motivo del Primer Congreso de esta Asociación, celebrado en Frankfurt, en 1910, tiene como objetivo básico proponer los temas de investigación que, a través de las comisiones pertinentes, centraría el trabajo científico de la mencionada sociedad profesional de modo inmediato. Pues bien, el tema que suscita Weber en primer lugar es la prensa, su importancia en la vida moderna, su capacidad de influir y de configurar esa misma vida. Se trata de desarrollar una Sociología de la Prensa ${ }^{3}$.

La prensa aparece, en primer término, como el órgano creador de un específico ámbito público (die Publizität) que es propio y diferencial de la vida moderna y que, en sus manifestaciones futuras, será también configurado por la prensa. Es evidente que lo público esconde, bajo una expresión unitaria, una pluralidad de referentes empíricos muy diversos entre sí. En cuanto a la historia más lejana, Weber alude sólo a la concepción de lo público en el mundo griego, tal como fuera descubierto, con sorpresa y

${ }^{2}$ Hans FreYer, Introducción a la Sociología, Madrid: Nueva Visión, 3." edición, 1951, pp. 14 y ss.

3 Para una exposición crítica de esta alocución, véase Hanno HARDT, Social Theories of the Press. Early German \& American Perspectives, Beverly Hills, Cal.: Sage, 1979, pp. 159-186. 
espanto, por Burckhardt. Pero, en uno de los pasajes más citados de su alocución, contrapone el concepto de lo público de mediados del siglo xvirI con el de comienzos del siglo xx, en el marco común de la vida parlamentaria: en la primera fecha, los periodistas que informaban sobre la vida parlamentaria en Inglaterra, estaban obligados a pedir perdón de rodillas ante el Parlamento por el breach of privilege -esto es, por la violación del privilegio de conocer en directo lo que en el Parlamento se trataba-; en 1910, cuando Max Weber escribe, la prensa es capaz de poner de rodillas al Parlamento con la sola amenaza de no publicar los discursos de los diputados. Ciertamente, tal cambio muestra el incremento del poder de la prensa en el mundo moderno, como ha señalado Hanno Beth ${ }^{4}$, pero, lo que sobre todo pretende resaltar Weber es el cambio en el modo de entender lo público y lo privado. Se trata de un verdadero tema controvertido, con variaciones locales, con opiniones encontradas y en constante evolución y, por tanto, de un tema vivo, que está haciéndose. Por ejemplo, ¿se considerará como pública la vida privada de los hombres públicos?5. Weber contrapone aquí el uso más discreto de la prensa inglesa y alemana al más abierto y extensivo de la prensa americana, y no deja de citar opiniones sobre el posible uso de la prensa como medio de control social, sacando «a la luz pública aquellos asuntos que no pueden ser sometidos a los tribunales de justicia»6.

Pero el ámbito de lo público configurado por la prensa no sólo refleja diferentes concepciones del mundo (Weltanschauungen), sino que está surcado por distintas relaciones de poder. No es cosa, sin embargo, de parafrasear y comentar cada pasaje del texto en toda su extensión. Valga adelantar que en él se plantean cuestiones de diversa índole: la constitución de la prensa como empresa capitalista y su demanda creciente de capital, el papel de los compradores y de los anunciantes, el papel de la prensa en la formación de la opinión pública, el eventual anonimato de los propietarios de los periódicos, los criterios de selección de la información, las agencias de noticias y sus relaciones internacionales, procedencia, formación y cualidades del profesional periodista, etc., etc.

Es evidente, en suma, que en este texto se ofrece compendiosamente el esquema básico para la construcción de una Sociología de la prensa y, más aún, de una Sociología de la comunicación social.

${ }^{4}$ Hanno BeTH y Harry Pross, Introducción a la ciencia de la comunicación, Barcelona: Anthropos, 1987, pp. 14-15.

5 Jürgen, Habermas, Historia y crítica de la opinión pública, Barcelona: Gustavo Gili, 1981, se propone el desarrollo del concepto de lo público a través de tres etapas: el mundo greco-romano, lo público estamental y lo público en sentido burgués. Esta última acepción es la que corresponde a lo público que se recoge en la opinión pública, si bien subsisten, con desigual importancia y en ámbitos restringidos, las acepciones de lo público procedentes de períodos históricos pasados.

${ }_{6}^{6}$ Estas tesis coinciden con las sostenidas por Edward A. Ross, Social Control. A Survey of the Foundations of Order (1901), aparecida bajo la forma de artículos entre 1896 y 1898. No sabemos si esta obra sería conocida por Weber. 